\title{
МАЛОГАБАРИТНАЯ СИСТЕМА ЭЛЕКТРОПИТАНИЯ МНОГОЛУЧЕВОГО КЛИСТРОНА
}

\author{
Косятова Алена Викторовна \\ Студент магистратуры \\ МИРЭА филиал \\ Научный руководитель: Ежов Михаил Алексеевич \\ Ведущий инженер НПК-6 АО \\ «НПП «ИСТОК» им. Шокина»
}

\begin{abstract}
Аннотация: В данной работе будет рассмотрена малогабаритная система электропитания многолучевого клистрона. Основная сложность при разработке заключается в очень жестких требованиях к передающим модулям по электрическим характеристикам, а также по условиям эксплуатации и массогабаритным параметрам. Рассматривается конструкция разрабатываемой системы.

Ключевые слова: Система питания, клистрон, усилитель СВЧ, электровакуумный прибор, модулятор, малогабаритный, многолучевой клистрон.
\end{abstract}

\section{SMALL-SIZED MULTIPATH KLYSTRON POWER SUPPLY SYSTEM}

Kosyatova Alena Viktorovna

Graduate student MIREA branch

Scientific adviser: Ezhov Mikhail Alekseevich Leading Engineer of NPK-6 JSC "NPP "ISTOK" them. Shokin 
Abstract: In this paper, the power supply system of a small-sized multipath klystron will be considered. The main difficulty in the development lies in the very strict requirements for transmitting modules in terms of electrical characteristics, as well as in terms of operating conditions and weight and size parameters. The design of developed system is considered.

Key words: Power supply system, klystron, microwave amplifier, electric vacuum device, modulator, small-sized, multipath klystron.

\section{Введение}

Мощные клистроны в настоящее время являются основными приборами, используемыми в качестве выходных каскадов усиления передатчиков радиолокационных станций (РЛС), работающих в коротковолновой части сантиметрового диапазона длин волн. Клистроны для РЛС должны обладать комплексом параметров: широкой полосой, большим уровнем выходной мощности, большой длительностью импульса, электропрочностью, большим сроком службы, определяемым в основном плотностью тока, отбираемого с катода. Наименьшие напряжения луча и модуляции являются еще одними немаловажными параметрами для обеспечения возможности получения минимальных массогабаритных характеристик аппаратуры.

Всем вышеперечисленным требованиям к усилительным СВЧ-приборам удовлетворяют многолучевые клистроны (МЛК). Мощные МЛК широко применяются в различных типах мобильных радиоэлектронных комплексов, так как низкие рабочие напряжения существенно упрощают изготовление источников питания [1].

Поэтому необходимо рассмотреть систему питания МЛК. Какие требования и параметры должны выполняться для работы в штатном режиме.

На рисунке 1 приведена структурная схема система питания малогабаритного многолучевого клистрона (СПММК). 


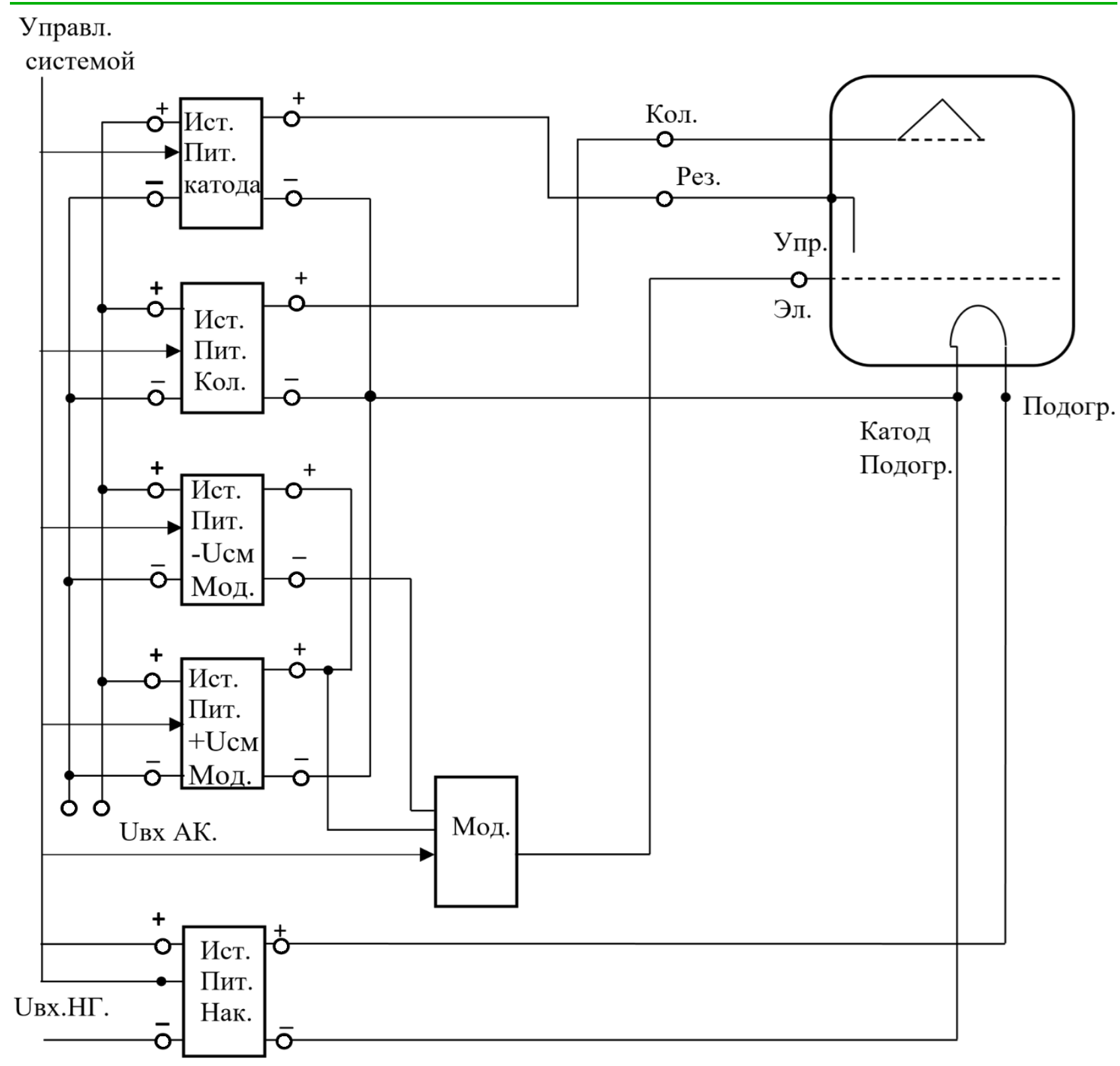

Рис. 1. Структурная схема система питания малогабаритного многолучевого клистрона

Как видно на рисунке 1 СПММК состоит из 5-ти источников питания и модулятора. Совместно с клистроном такие устройства называют передающим модулем (ПМ) или усилителем СВЧ.

Основная сложность при разработке заключается в очень жестких требованиях к ПМ по электрическим характеристикам, а также по условиям эксплуатации и массогабаритным параметрам.

Далее будет рассмотрены эти требования.

Электрические параметры системы питания определяет - клистрон. 
Клистрон - это электровакуумный СВЧ-прибор, в котором преобразование постоянного потока электронов в переменный происходит путем модуляции скоростей электронов электрическим полем СВЧ и последующей группировки электронов в сгустки в пространстве дрейфа, свободном от поля СВЧ [2].

Источник питания катода может быть стабилизированным и менее $1 \%$, то есть выходное напряжение не зависит от тока нагрузки и нестабилизированным: выходное напряжение зависит от тока нагрузки.

Параметры источника питания катода, следующие: $\mathrm{U}_{\text {кат }}=-1,3$ кB $\div-4$ кB;

$$
\mathrm{I}_{\text {кат }}-30 \mathrm{мA} \div 250 \mathrm{мA} \text {. }
$$

Пульсации гармонические имеют характеристики: $20 \div 30$ мВ или Uкат $\times 10^{-5}$.

Источник питания накала регулируемый со стабильностью меньше $3 \%$, напряжением Uнак $=4$ B $\div 4,8$ B, ток Інак-1,5 A $\div 2$ А. Источник должен иметь развязку больше 4 кВ, так как подключатся относительно Uкат.

Для ПМ с малым временем готовности источник питания накала должен иметь два режима «Форсаж» и «Рабочий».

Параметры «рабочего» режима были описаны выше.

Параметры режима «форсаж» следующие:

Uнак= 6 кВ, Інак= 6 A.

Источник при подаче входного напряжения должен в течение 5-6 секунд работать в режиме «форсаж», а затем автоматически перейти в рабочий режим.

Источник питания модулятора-( «-Uсм» $=-300$ В $\div-700$ В, Імод $\leq 70$ мА $)$ это напряжение является запирающем для клистрона. Подключается относительно катода и должен иметь развязку более 4 кВ.

Источник питания вольтодобавки является регулируемым и имеет характеристики, «+ Uсм» $=0 \mathrm{~B} \div 100 \mathrm{~B}$, Ів/д $\leq 3$ мА и так же должен иметь развязку $>4$ кВ так как подключатся относительно катода.

Модулятор - это устройство, которое периодически подключают к управляющему электроду клистрона, если «+ Uсм»- клистрон открыт, если «-Uсм» - то клистрон закрыт. 
Модулятор характеризуется следующими параметрами:

Амплитуда выходных импульсов: $\leq 700$ В

Частота выходных импульсов: fмод $=1$ кГц $\div 700$ Гц

Скважность выходных импульсов: $Q=\frac{T}{t_{u}}=2 \div 30$

Скорость нарастания напряжения или длительность фронтов включения и срыва модулятора: 30 нсек $\div 70$ нсек.

Неравномерность верхней границы («полки») импульса не более 3\% от амплитуды выходного импульса.

Выходные импульсы модулятора подаются относительно катода, поэтому требуется развязки более 4 кВ.

Специфика работы ПМ в том, что он работает в двух режимах: дежурномвключен источник питания накала, который работает непрерывно до 4-х часов. И второй режим активный, который, как правило, работает $10 \div 30$ секунд.

Поэтому система питания имеет два первичных источника.

$\mathrm{U}_{\mathrm{Hг}}$ - для источник питания накала $(23,5-35,5 \mathrm{~B} \leq 3 \mathrm{~A})$

$\mathrm{U}_{\mathrm{AK}}$ - для источников питания Uкат., Uкол., «+ Uсм», «- Uсм».

Во время эксплуатации система питания получает первичную энергию от химических батарей с ограниченным запасом энергии. Отсюда вытекает жесткие требования к КПД системы.

КПД источников Uкат., Uкол., «+ Uсм», «- Uсм» $\geq 86 \%$

КПД источников питания накала Uнак. $\geq 70 \%$

Еще одно обязательное требование к системе питания, она должна иметь возможность синхронизации внешним генератором.

ПМ в большинстве случаев применяются в бортовых устройствах военного назначения поэтому условия эксплуатации определяются требованиями к этим устройствам.

Эти требования накладывают ограничения на применяемую элементную базу, материалы, а также на конструкцию.

Конструктивно система питания оформлена как отдельный блок, внутри которого есть отсеки с закрепленными в них функциональными узлами системы питания. Отсеки в конструкции выполняют несколько задач: 
1. Придают блоку дополнительную механическую прочность.

2. Обеспечивают простоту заливки изолирующими компаундами высоковольтных и высокопотенциальных узлов.

3. Увеличивают электромагнитную совместимость функциональных узлов.

4. Увеличивают площадь тепловыводящей поверхности блока.

Отсеки для высоковольтных и высокопотенциальных узлов изолированы от корпуса.

Для того чтобы обеспечить очень жесткие требования к габаритам и массе блока все соединения между функциональными узлами выполняются без жгутов при помощи межплатных разъемов.

Самая сложная задача при конструировании - это обеспечение минимального теплового сопротивления между корпусом блока и активными элементами (диоды, транзисторы) которые еще и должны быть изолированы от корпуса.

Данное требование определяется тем, что блок работает в замкнутом объеме и охлаждение силовых элементов происходит только за счет теплоемкости корпуса блока и несущих конструкций.

Проведя расчеты и моделирование блока, получились следующие параметры:

$$
\begin{aligned}
& \text { объем }(\mathrm{V})=1,1 \mathrm{~m}^{3} ; \\
& \text { масса }(\mathrm{m})=1,6 \div 2,0 \text { кг; } \\
& \mathrm{P}_{\text {вых }}=650 \text { Вт. }
\end{aligned}
$$

В качестве примера на рисунке 2 приведен общий вид системы электропитания МКЛ. 

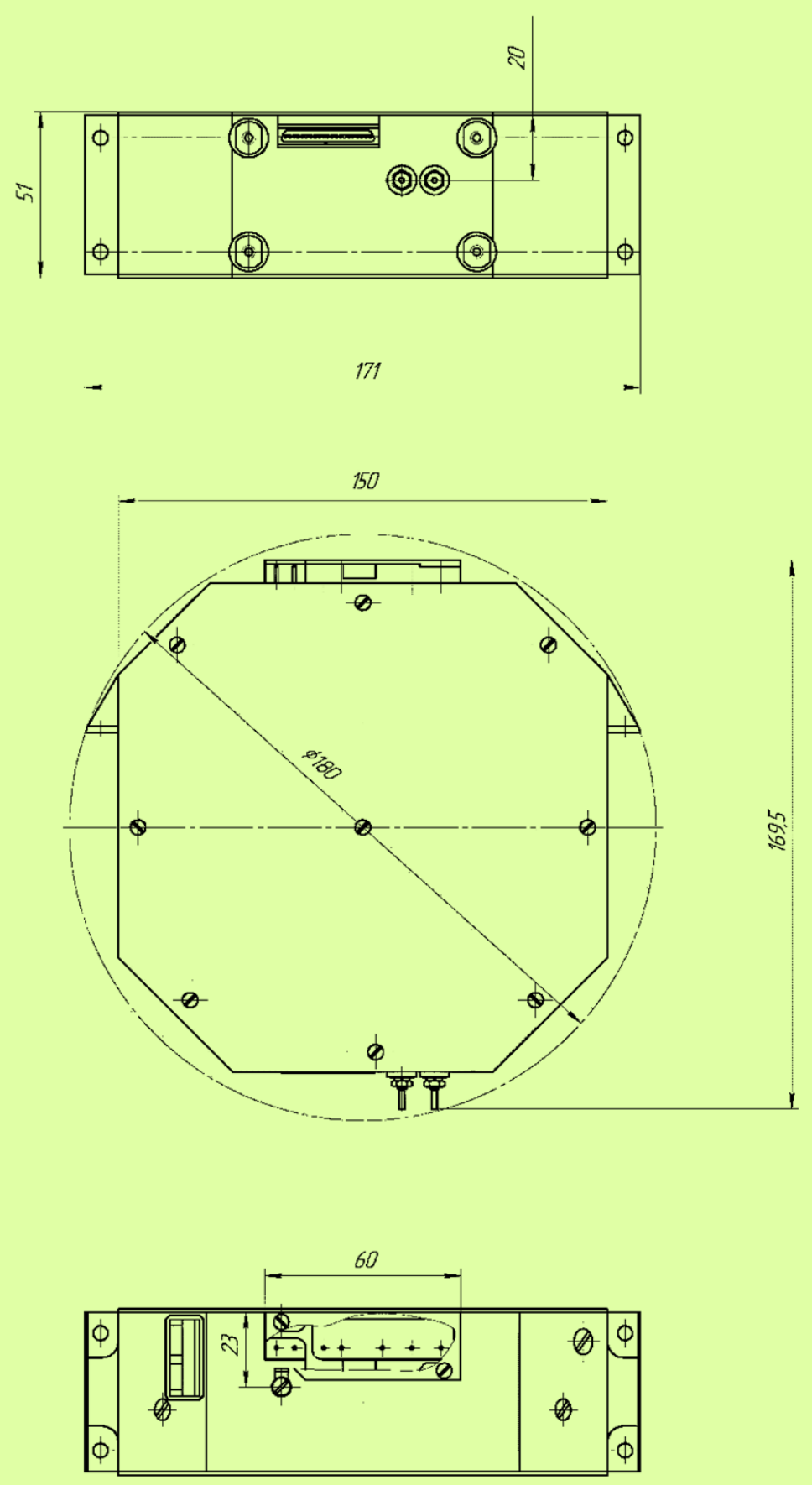

\section{Рис. 2. Общий вид системы}

Наша промышленность не выпускает серийно силовые элементы, которые удовлетворяют вышеприведенным требованиям, поэтому в большинстве случаев это проблема, которая ложится на разработчика системы питания. Как правило, организуется мелкосерийное производство изолированных диодных и транзисторных сборок.

В заключение хотелось бы отметить, что конечный результат во многом зависит от мастерства и таланта разработчика, конструктора и технолога. 


\section{Список литературы}

1. С.Г.Асташов, В.И.Пугнин, С.А.Мельников, А.С.Арефьев, А.Н. Юнаков. Разработка конструкции выходной системы мощного многолучевого клистрона

2. http://vstu-physics.github.io/mwelectronics/\%D0\%BA\% D0\%BE\%D0\% B B\%D0\%B5\%D0\%B1\%D0\%B0\%D0\%BD\%D0\%B8\%D1\%8F/2014/09/08/klystron/

3. Мелешин В.И. Транзисторная преобразовательная техника. -М: Техносфера,2005. - 632c. 